\title{
Expanding EAL expertise: Taking a multilingual stance
}

\author{
Ester J. de Jong \\ University of Florida
}

Abstract: English as an Additional Language (EAL) students are increasingly taught by non-specialist, mainstream teachers. This trend calls for a reconceptualization of teacher education to explicitly and purposefully include linguistically and culturally responsive pedagogy in their curriculum. In the United States, several frameworks have been proposed to address this need, although much still needs to be learned about actual practice in preservice teacher preparation programs. In this article, I caution against the monolingual bias in preservice teacher preparation and argue for the mandate for developing a multilingual stance for all teachers of EAL students.

Key words: pre-service teacher education, EAL, English language learners, multilingual pedagogies

\section{Introduction}

Four years ago, I had the honor and pleasure of giving a keynote at the ACTA 2014 conference in Melbourne. My focus was on the on-going marginalization of English as an Additional Language (EAL) teacher expertise that had followed a perfect storm of educational developments for over a decade in the United States: the continued increase in the number of EAL students, specialist EAL and bilingual education teacher shortage, the shift from 'language-based' to content-based language teaching. Collectively, these developments intentionally and unintentionally prioritized the mainstream classroom as the 'best' placement for EAL students. These trends in the field subsequently combined with federal and state accountability regimes that required high stakes standardized testing and resulted in a significant standardization of curriculum and instruction along monolingual and monocultural lines. Rather than re-imagining mainstream 
classrooms from a linguistic and cultural perspective and ensuring equal access to high-quality schooling, EAL teachers and their expertise were pushed to the margins.

I also argued that teaching EAL students had been framed merely as a matter of 'just good teaching' and this assumption guided professional development efforts. The "Just Good Teaching (JGT)" orientation (Harper \& de Jong, 2004) assumes that teaching bilingual learners is not essentially different from teaching any (struggling) learner and does not require additional or different professional development. The keynote argued for the need for on-going specialized expertise related to the role of language and culture in schools in order to ensure that all teachers could engage in practices that would equitably support their EAL students (see de Jong \& Harper, 2005; Harper \& de Jong, 2009; Harper, de Jong, \& Platt, 2008, for our work in this area). These observations applied not only to the United States but referenced a development observed previously in other in other English language countries, including the United Kingdom and Australia (e.g., Davison, 2001; Hammond \& Derewianka, 1999; Leung \& Franson, 2001; Moore 2007).

Fast forward to four years later - this time the ACTA conference in Adelaide in October of 2018. The struggle to define, develop and, most importantly, legitimize EAL expertise continues at all levels in the United States as well as Australia: early learning, primary and secondary schools, and post-secondary education, including teacher preparation. The dominance of the mainstream and the JGT perspective is also, unfortunately, alive and well in both contexts (e.g., Cross, 2012). My presentation focused on teacher preparation and the mandate to develop a multilingual perspective as we prepare all teachers to work with EAL students, including mainstream teachers. This article first outlines a few key developments in the United States as it relates to mainstream teacher preparation for working with EAL students. It then shows why taking a bi/multilingual stance is important and cautions against a monolingual bias in our work with mainstream teachers. It concludes with ways we can bring a multilingual perspective into our work as teacher educators. Although the emphasis in the sections below is on work done in North America, many parallels exist with the Australian context and hopefully this article will spark a fruitful dialogue and collaboration among researchers and practitioners across contexts. 


\section{Preparing teachers to work with EAL students: A North American perspective}

The issue of EAL teacher expertise and how it should contribute to and inform decisions about the schooling of EAL learners continues to be a key issue in the field. The increased placement of English language learners (ELLs) in mainstream U.S. classrooms and their continued pattern of academic underachievement have led to a consistent call for better mainstream teacher preparation (Gándara \& Santibañez, 2016).

A variety of teacher preparation frameworks have been proposed to address the knowledge and skills for mainstream teachers to develop for working specifically with EAL students (e.g., de Jong \& Harper, 2005; de Jong, Harper, \& Coady, 2013; Lucas \& Grinberg, 2008; Lucas \& Villegas, 2010, 2013). Collectively, these frameworks call for knowledge about language, language variation, second language development as well as deep understandings of EAL students and how their cultural and linguistic experiences intersect with learning in U.S. school settings and sociopolitical realities (Coady, Harper, \& de Jong, 2011). Strategies to facilitate the integration of language and content, to provide comprehensible input in the target language, and to explicitly scaffold academic English language proficiency development are foundational pedagogical tools, as are ways that teachers can assess and build on students' cultural funds of knowledge and background knowledge.

The disturbing reality in the United States is that mainstream teacher preparation for EAL students has not been approached systemically and varies greatly from state to state. A recent report from the Education Commission of States (2014) notes that 20 states explicitly require EAL teachers to have specialist certification. Only five states require mainstream teacher preparation, although some states acknowledge the needs of English language learners. Fifteen states do not identify any requirement for EAL teacher preparation, certification, or endorsements appear to be optional (Ballantyne, Sanderman, \& Levy, 2008; Education Commission of the States, 2014; Samson \& Collins, 2012). Furthermore, teacher certification exams and district-based observation tools do not include content related to teaching EAL students (Samson \& Collins, 2012). In fact, less than one-sixth of colleges offering preservice teacher preparation include training on working with English language learners (Ballantyne, Sanderman, \& Levy, 2008). It is therefore not surprising that many preservice and practicing 
mainstream teachers continue to report that they feel unprepared and inefficacious when it comes to working with bilingual learners (Ballantyne, Sanderman, \& Levy, 2008; Coady, Harper, \& de Jong, 2016; Karabenick \& Noda, 2004).

In addition to these despairing statistics, we still have much to learn about what makes for effective practices in mainstream initial teacher preparation (Villegas, SaizdeLaMora, Martin, \& Mills, 2018). Research notes the importance of field experiences to build this EAL-specific knowledge and skill base (Lee, Kim, \& de Jong, 2018). Structured and explicitly scaffolded opportunities have shown to enhance preservice teachers' beliefs and attitudes toward EAL students (Coates, 2016; Daniel, 2014; Pettit, 2011) and to facilitate theory to practice connections (Ariza, 2003; Salerno \& Kibler, 2013). Other studies contest that, without program-wide 'infusion' of English language learner -specific knowledge and skills, it is unlikely that preservice candidates will be prepared to engage in practices that reflect a specific understanding of EAL students and their needs (Costa, McPhail, Smith, \& Brisk, 2005; Levine \& Howard, 2014; Nutta, Mokhtari, \& Strebel, 2012). Moreover, without attention to the preparation of general education teacher educators, opportunities to meaningfully include more specialized knowledge and skills related to EAL teaching and learning into their course work are likely to be greatly diminished (de Jong, Naranjo, Li, \& Ouzia, 2018; Faltis \& Valdés, 2016).

Clearly, much still needs to be done in research, practice, and policy. In what follows, I argue that, when we consider the professional development for preservice and in-service (practicing) mainstream teachers, we need to help them challenge mainstream classroom contexts as monolingual learning environments and take a multilingual stance.

\section{Beyond monolingual mainstream classrooms}

Mainstream (general education, content) classrooms are often considered monolingual classrooms by default, rather than choice. After all, these classrooms are officially English-medium classrooms with English-language curriculum, materials, and English-language assessments. Moreover, assuming native English speakers as the students in the classroom leads to monolingual instructional practices and, as noted above, an assumption that those practices are relevant for all students. In the United States, these monolingual realities are further exacerbated by the fact that most mainstream teachers are monolingual in English. Few 
have grown up bilingually or choose to learn a world language in college. As a result, they tend to have limited experiences with other languages and cultures (e.g., through study abroad). It should therefore not come as a surprise that many conclude that mainstream classrooms are monolingual settings by necessity (de Jong, 2013). Multiliteracy development and bi/multilingual practices are assumed to be the domain of the teacher with high levels of proficiency in English and the partner language (Schwarzer, Haywood, \& Lorenzen, 2003).

However, even in English-medium contexts effective English teachers strategically use students' home language resources for multiple purposes, such as clarifying and assessing content learning, building social relationships, teaching key concepts, making crosslinguistic connections (Gersten \& Baker, 2000; Karathanos, 2010; Lucas \& Katz, 1994). This holds true not only for English-dominant settings, such as the United States or Australia, but also in other settings where English is used to teach language as well as content, such as Hong Kong (Lin, 2006) and in Europe (Lin \& He, 2017; Nikula \& Moore, 2016). In addition to the importance for school achievement, studies on bilingualism continue to point to the cognitive benefits of bilingualism of young children as well as older adults, and the economic impact bilingual skills can have on the individual and society (Gándara \& Callahan, 2014).

It is therefore imperative that teachers build on EAL students' entire linguistic and cultural repertoire (Cummins \& Early, 2011). It not only affirms their identities but also connects new learning to what they already know (Cummins, Bismilla, Chow, Giampapa, Cohen, Leoni, \& others, 2005). It acknowledges that learning for bilinguals happens across languages as students use their full linguistic repertoires for participation, content learning, critical thinking and problem solving, identity construction, and the development of metalinguistic awareness. It helps them make sense of their lived experiences and the world around them (Garcia \& Wei, 2014). As noted by the Council of Europe (2001, p. 43),

The learner of a second or foreign language and culture does not cease to be competent in his or her mother tongue and the associated culture. Nor is the new competence kept entirely separate from the old. The learner does not simply acquire two distinct, unrelated ways of acting and communicating. The language learner becomes plurilingual and develops interculturality. 
As early as 1989, Francois Grosjean expressed this same notion by warning us that "bilinguals are not two monolinguals in one person" (p. 4). He critiqued the notion of 'balanced' bilinguals and holding bilinguals to monolingual standards and stressed the contextualized nature of bilingualism.

Important for our discussion is that the notion that bilinguals are unique individuals and that instruction should respond to their $\mathrm{bi} /$ multilingual realities is not something that applies solely in the context of dual language programs but goes beyond any particular program: bilinguals are bilinguals whether they find themselves in a mainstream, an EAL or a bilingual education classroom (de Jong, 2011). Districts can engage in bilingual practices through the establishment of maintenance bilingual programs, but also through collaboration with community-based heritage language programs, and/or encourage classroom practices that affirm students' entire linguistic repertoires. Which strategies are most appropriate will depend on community resources and broader context of schooling and can be conceptualized along a continuum of bi/multilingual practices (de Jong \& Freeman, 2010).

\section{Preparing all teachers: Toward a multilingual stance}

In order to provide an optimal learning environment for EAL students, all teachers must therefore be able to engage in practices that recognize students' multilingual lived worlds and treat students' linguistic and cultural experiences as assets rather than liabilities when making decisions about curriculum, pedagogy, and assessment (de Jong, 2011; Ruiz, 1984). Another way of framing this is that all teachers need to take a multilingual stance when working with linguistically and culturally diverse students. García and Kleyn (2016, p. 21) define this stance as one that claims, "bilingualism is a resource at all times to learn, think, imagine, and develop commanding performances in two or more languages." Teachers who take a multilingual stance position linguistic and cultural diversity as a resource they can draw on and expand in an additive and dynamic approach (de Jong, 2011).

While perhaps a self-evident stance in bilingual teacher preparation, this principle can be more challenging in the context of mainstream or general education teacher preparation. It challenges teacher educators to consider how they are preparing their monolingual mainstream teachers to embrace a multilingual stance and enact it into practice. As noted earlier, approaches to 
prepare mainstream teachers commonly include key elements that relate to English as an additional language: knowledge of second language acquisition, the role of culture in schooling, scaffolding strategies to provide comprehensible input (in English) and connecting to students' prior learning experiences, and strategies for supporting students' development of academic language proficiency (in English). The overarching emphasis is on EAL students' access to the curriculum in and through English. Knowledge of the role of the students' home language in learning another language and the value of respecting students' home languages and cultures are often included to build awareness and (more) positive attitudes towards use of language other than English in the classroom (e.g., Li \& Peters, 2016). Engaging preservice teacher candidates in using bi/multilingual practices is typically absent from the curriculum, especially practices that go beyond their use as a temporary bridge to learning English (Coleman, 2012; de Jong \& Gao, 2019). Moreover, mainstream teachers who self-identify as monolingual may not be comfortable with or may question the use of multilingual pedagogies. Developing preservice teacher candidates' multilingual stance therefore poses a challenge to teacher educators.

In fact, a review of the literature on mainstream (monolingual) teachers and bi/multilingual practices in the United States identified few studies with a focus on preservice teachers. Most studies provide examples of practicing teachers using a wide range of bi/multilingual strategies (Krulatz \& Neokleous, 2017). Ernst-Slavit and Mulhern (2003), for instance, discuss the flexible use of bilingual books for cross-linguistic comparisons, for background building, and for constructing community in the classroom. Through the eyes of a mainstream classroom teacher, Schwarzer, Haywood, and Lorenzen (2003) describe how she used multilingual teaching strategies, including posting multilingual labels and inviting community members to share their languages and cultures. Pappamihiel and Lynn (2014) and Giambo and Szecsi (2015) present additional strategies around text (using cognates, dialogue journals, bilingual note taking) and using technology as a resource for accessing students' various home languages.

These multilingual pedagogies that have been observed in mainstream classroom realities could indeed be transferred into a teacher education program through modeling and practice, but few examples have been documented. Evans, Arnot-Hopffler, and 
Jurich (2005) and Catalano and Hamann (2016) are two interesting exceptions as they focus specifically on efforts in the context of preservice teachers. Evans and her colleagues brought bilingual and mainstream teacher candidates together in one class in order to develop a shared sense of ownership and responsibility for teaching EAL students. Through readings, guest speakers, field trips to cultural and community-based events, and bilingual class activities, the courses created spaces for - often challenging conversations among the students that allowed for the exploration of issues of equity, cultural diversity and prejudice. At the end, mainstream teacher candidates indicated their increased awareness of these issues as well as a better understanding of bilingual strategies, as they had been modelled in the program.

Catalano and Hamann (2016) argue for the importance of developing mainstream teacher candidates' language awareness and proficiencies as part of mainstream teacher education for EALs. In this article, they identify several translanguaging strategies for teacher educators across different courses, including reading (auto)biographies of bilingual adults and children, encouraging readings in languages other than English, studying a language through different means (technology, in-person tutoring) and conducting cross-linguistic comparisons, and micro-teaching activities that require students to include multilingual pedagogies.

These studies show not only the possibility of bi/multilingual pedagogies but also the positive impact a multilingual stance has on teachers and students alike. To take a multilingual stance, requires teacher candidates to be able to pro-actively make multilingual practices the norm in their teaching and learning. In addition to the strategies mentioned above, teacher educators could consider the following additional strategies combined with a research agenda that enhances our understanding of teacher candidates' multilingual stance development:

- Purposefully drawing on the experiences of teacher candidates who themselves have grown up bilingually and their schooling experiences.

- Articulating and explicitly addressing teacher candidate's knowledge of the pluralistic dimensions of EAL learning and development (e.g., State of Victoria curriculum guidelines, https://www.vcaa.vic.edu.au/Pages/ foundation $10 /$ viccurriculum/eal/intro.aspx)

- Enhancing teacher candidates' bilingual proficiency development through taking world language classes and/ or study abroad (e.g., de Jong, 2013) 
- Designing field experiences that include working directly with EAL students and that include structured opportunities for reflection (Lee, Kim, \& de Jong, 2018; Villegas, SaizdeLaMora, Martin, \& Mills, 2018).

If we want all teachers to be able to build on students' entire linguistic repertoire, the development of a multilingual stance in mainstream candidates is imperative. Although addressing mainstream teachers' beliefs may be a first step in this process (e.g., Pettit, 2011), it is important that teacher education moves beyond positive attitudes and tolerance for EAL's use of their home language in the classroom (Molyneux, 2009).

\section{Conclusion}

Cummins and colleagues note, "It is hard to argue that we are teaching the whole child when school policy dictates that students leave their language and culture at the schoolhouse door" (Cummins et al., 2005, p. 38). While English may be the primary medium of instruction in mainstream classrooms, they do not have to be monolingual sites of learning. Teachers and students resist the monolingual bias and can choose to engage in multilingual pedagogies and language practices. Taking a multilingual stance is not only desirable, but a must-do if we want linguistically and culturally diverse students to succeed in school.

\section{References}

Ariza, E. N. (2003). TESOL tutor time homework center: A collaboration of volunteer preservice teachers in the public elementary schools. Urban Education, 38(6), 708-724. doi:10.1177/0042085903257316

Ballantyne, K. G., Sanderman, A.R., \& Levy, J. (2008). Educating English language learners: Buildingteachercapacity. Washington, DC: National Clearinghouse for English Language Acquisition.

Catalano, T. \& Hamann, E.T. (2016). Multilingual pedagogies and pre-service teachers: Implementing "language as a resource" orientations in teacher education programs. Bilingual Research Journal, 39(3-4), 263-278. doi:10.1080/ 15235882.2016.1229701

Coady, M., Harper, C., \& de Jong, E. (2011). From preservice to practice: Mainstream elementary teacher beliefs of preparation and efficacy with English language learners in 
the state of Florida. Bilingual Research Journal, 34(2), 223-239. doi:10.1080/15235882.2011.597823

Coady, M. R., Harper, C., \& de Jong, E. J. (2016). Aiming for equity: Preparing mainstream teachers for inclusion or inclusive classrooms? TESOL Quarterly, 50(2), 340-368. doi: $10.1002 /$ tesq.223

Coates, P. W. (2016). To build a culturally sensitive educator: A clinical model highlighting the importance of innovative ESL strategies in early field placement classes teaching ELL middle level students. Theory and Practice in Language Studies, 6(3), 445-451. doi:http://dx.doi.org/10.17507/tpls.0603.01

Coleman, J. (2012), Moving beyond an 'instrumental' role for first languages of English language learners. TESOL in Context, 22 (1), 18-37.

Costa, J., McPhail, G., Smith, J., \& Brisk, M. E. (2005). Faculty first: The challenge of infusing the teacher education curriculum with scholarship on English language learners. Journal of Teacher Education, 56(2), 104118. doi:10.1177/0022487104274119

Council of Europe (2001). Common European Framework of Reference for Languages: Learning, Teaching, Assessment. Strasbourg: Cambridge University Press.

Cross, R. (2012). Reclaiming the territory: Understanding the specialist knowledge of ESL education for literacy, curriculum, and multilingual learners, TESOL in Context, 22(1), 4-17.

Cummins, J., Bismilla, V., Chow, P., Giampapa, F., Cohen, S., Leoni, L., Sandhu, P., \& Sastri, P. (2005). Affirming identity in multicultural classrooms. Educational Leadership, 63(1), $38-43$.

Cummins, J., \& Early, M. (Eds.). (2011). Identity texts. The collaborative creation of power in multilingual schools. London, England: Trentham Books.

Daniel, S. M. (2014). Learning to educate English language learners in pre-service elementary practicums. Teacher Education Quarterly, 41(2), 5-28. Retrieved from http://www. jstor.org/stable/teaceducquar.41.2.5

Davison, C. (2001). ESL in Australian schools: From the margins to the mainstream. In B. Mohan, C. Leung, \& C. Davison 
(Eds.), English as a second language in the mainstream: Teaching, learning and identity (pp. 11-29). London: Pearson.

de Jong, E. J. (2011). Foundations for multilingualism in education: From principles to practice. Philadelphia, PA: Caslon Inc.

de Jong, E. J. (2013). Preparing mainstream teachers for multilingual classrooms, Association of Mexican American Educators Journal, 7(2), 40-49. Retrieved from http:// amaejournal.utsa.edu/index.php/amae/article/view/125

de Jong, E. J., \& Freeman, R. (2010). Bilingual approaches. In C. Leung \& A. Creese (Eds.), English as an additional language: Approaches to teaching linguistic minority students (pp. 108122). London: SAGE.

de Jong, E. J., \& Gao, J. (2019). Taking a multilingual stance: A continuum of practices. Minnesota TESOL Journal, 35 (1). Retrieved from http://minnetesoljournal.org/currentissue/mtj-2019-1/taking-a-multilingual-stance-a-continuumof-practices/

de Jong, E. J., \& Harper, C. A. (2005). Preparing mainstream teachers for English language learners: Is being a good teacher good enough? Teacher Education Quarterly, 32(2), 101-124. Retrieved from http://www.jstor.org/ stable/23478724

de Jong, E. J., Harper, C. A., \& Coady, M. (2013). Enhanced knowledge and skills for elementary mainstream teachers of English language learners. Theory into Practice, 52 (2), 89-97. doi:10.1080/00405841.2013.770326

de Jong, E. J., Naranjo, C., Li, S., \& Ouzia, A. (2018). Beyond compliance: ESL faculty's perspectives on preparing general education faculty for ESL infusion, The Educational Forum, 82 (2), 174-190. doi:10.1080/00131725.2018.1420856

Education Commission of States (2014). What training if any, is required of general classroom teachers. Retrieved 24 February 2019, from http://ecs.force.com/mbdata/ mbquestNB2?rep=ELL1415

Ernst-Slavit, G., \& Mulhern, M. (2003). Bilingual books: Promoting literacy and biliteracy in the second-language and mainstream classroom. Reading Online, 7(2), 1096-1232.

Evans, C., Arnot-Hopffler, E., \& Jurich, D. (2005). Making ends meet: Bringing bilingual education and mainstream students together in preservice teacher education. Equity Ev Excellence in Education, 38(1), 75-88. doi:10.1080/10665680590907855 
Faltis, C. J., \& Valdés, G. (2016). Preparing teachers for teaching in and advocating for linguistically diverse classrooms: A vade mecum for teacher educators. In D. H. Gitomer \& C. A. Bell (Eds.), Handbook of research on teaching ( $5^{\text {th }}$ ed.) (pp. 549-592). Washington, DC: American Educational Research Association.

Gándara, P., \& Callahan, R. (2014). The bilingual advantage: Language, literacy, and the US Labor Market. Bristol, UK: Multilingual Matters.

Gándara, P., \& Santibañez, L. (2016). The teachers our English language learners need. Educational Leadership, 73(5), 32-37.

García, O., \& Kleyn, T. (2016) (Eds.), Translanguaging with multilingual students. Learning from classroom moments. New York, NY: Routledge.

García, O. \& Wei, L. (2014). Translanguaging: Language, bilingualism and education. Basingstoke, UK: Palgrave Macmillan.

Gersten, R., \& Baker, S. (2000). What we know about effective instructional practices for English-language learners. Exceptional Children, 6(4), 454-470. doi:10.1177/001440290006600402

Giambo, D. A., \& Szecsi, T. (2015). Promoting and maintaining bilingualism and biliteracy: Cognitive and biliteracy benefits \& strategies for monolingual teachers. The Open Communication Journal, 9(1), 56-60. doi:10.2174/1874916X01509010056

Grosjean, F. (1989). Neurolinguists, beware! The bilingual is not two monolinguals in one person. Brain and Language, 36, 3-15. doi:https://doi.org/10.1016/0093-934X(89)90048-5

Hammond, J., \& Derewianka, B. (1999). ESL and literacy education: Revisiting the relationship. Prospect, 14(2), 24-39.

Harper, C. A., \& de Jong, E. J. (2004). Misconceptions about teaching ELLs. Journal of Adolescent and Adult Literacy, 48(2), 152-162. doi:10.1598/JAAL.48.2.6

Harper, C. A., \& de Jong, E. J. (2009). English language teacher expertise: The elephant in the room. Language and Education, 23(2), 127-151. doi:10.1080/09500780802152788

Harper, C. A., de Jong, E. J., \& Platt, E. (2008). Marginalizing English as a second language teacher expertise: The exclusionary consequence of No Child Left Behind. Language Policy, 7(3), 267-284. doi:10.1007/s10993-008-9102-y 
Karabenick, S. A., \& Noda, P. A. (2004). Professional development implications of teachers' beliefs and attitudes toward English language learners. Bilingual Research Journal, 28, (1), 55-75. doi:10.1080/15235882.2004.10162612

Karathanos, K. A. (2010). Teaching English language learner students in US mainstream schools: intersections of language, pedagogy, and power. International Journal of Inclusive Education, 14(1), 49-65. doi:10.1080/13603110802504127

Krulatz, A., \& Neokleous, G. (2017). Helping teachers to move from 'English corners' to 'Multilingual corners' in the language classroom. Teacher Trainer, 31(3), 20-22. Retrieved from www.tttjournal.co.uk

Lee, Y., Kim, H., \& de Jong, E. J. (2018). Becoming a teacher of culturally and linguistically diverse students: Elementary pre-service teachers' ESL field experiences working with English language learners, Sunshine State TESOL Journal, 12 (1), 29-40. Retrieved from https://sunshinestatetesol. wildapricot.org/SSTESOL-Journal-Past-Issues

Levine, T. H., \& Howard, E. R. (2014). Teacher educator capacity to prepare preservice teachers for work with emergent bilinguals. In T. H. Levine, E. R. Howard, \& D. M. Moss (Eds.), Preparing classroom teachers to succeed with second language learners (pp. 17-36). New York, NY: Routledge.

Leung, C., \& Franson, C. (2001). Mainstreaming: ESL as a diffused curriculum concern. In B. Mohan, C. Leung, \& C. Davison (Eds.), English as a second language in the mainstream: Teaching, learning and identity (pp. 11-29). London: Pearson.

Li, N., \& Peters, A. W. (2016). Preparing K-12 teachers for ELLs: Improving teachers' L2 knowledge and strategies through innovative professional development. Urban Education, 1-18. doi:10.1177/0042085916656902

Lin, A. M. Y. (2006). Beyond linguistic purism in language-ineducation policy and practice: Exploring bilingual pedagogies in a Hong Kong science classroom. Language and Education, 20(4), 287-305. doi:10.2167/le643.0

Lin, A. M. Y., \& He, P. (2017). Translanguaging as dynamic activity flows in CLIL classrooms, Journal of Language, Identity E Education, 16(4), 228-244. doi:10.1080/15348458. 2017.1328283 
Lucas, T., \& Grinberg, J. (2008). Responding to the linguistic reality of mainstream classrooms: Preparing all teachers to teach English language learners. In M. Cochran-Smith, S. Feiman-Nemser, \& D. J. McIntyre (Eds.), Handbook of research on teacher education: Enduring questions in changing contexts (3rd ed.) (pp. 606-636). New York, NY: Routledge.

Lucas, T., \& Katz, A. (1994). Reframing the debate: The roles of native languages in English-only programs for language minority students. TESOL Quarterly, 28 (3), 537-561. doi: $10.2307 / 3587307$

Lucas, T., \& Villegas, A. M. (2010). A framework for preparing linguistically responsive teachers. In T. Lucas (Ed.), Teacher preparation for linguistically diverse classrooms (pp. 75-92). Routledge.

Lucas, T., \& Villegas, A. M. (2013). Preparing linguistically responsive teachers: Laying the foundation in preservice teacher education. Theory Into Practice, 52(2), 98-109. doi:10 $.1080 / 00405841.2013 .770327$

Molyneux, P. (2009). Education for biliteracy: Maximising the linguistic potential of diverse learners in Australia's primary schools. Australian Journal of Language and Literacy, 32(2), 97-117.

Moore, H. (2007). Non-language policies and ESL: Some connections. TESOL Quarterly, 41 (3), 573-83. doi:10.1002/j.1545-7249.2007.tb00089.x

Nikula, T., \& Moore, P. (2016). Exploring translanguaging in CLIL. International Journal of Bilingual Education and Bilingualism. doi:10.1080/13670050.2016.1254151

Nutta, J., Mokhtari, K., \& Strebel, C. (2012). Preparing every teacher to reach English learners: A practical guide for teacher educators. Cambridge, MA: Harvard Education Press.

Pappamihiel, E., \& Lynn, C. A. (2014). How can monolingual teachers take advantage of learners' native language in class? Childhood Education, 90(4), 291-297. doi:10.1080/00094056. 2014.937258

Pettit, S. K. (2011). Teachers' beliefs about English language learners in the mainstream classroom: A review of the literature. International Multilingual Research Journal, 5(2), 123-147. doi: 10.1080/19313152.2011.594357

Ruiz, R. (1984). Orientations in language planning. Journal of the 
National Association for Bilingual Education, 8, 1-14. doi:10.10 80/08855072.1984.10668464

Salerno, A. S., \& Kibler, A. K. (2013). Before they teach: How preservice teachers plan for linguistically diverse students. Teacher Education Quarterly, 40(4), 5-26. Retrieved from www.jstor. org/stable/teaceducquar.40.4.5

Samson, J., \& Collins, B. (2012). Preparing all teachers to meet the needs of English language learners. Washington, D. C.: Center for American Progress. Retrieved May 29 ${ }^{\text {th }}$, 2017 from http://files.eric.ed.gov/fulltext/ED535608.pdf

Schwarzer, D., Haywood, A., \& Lorenzen, C. (2003). Fostering multiliteracy in a linguistically diverse classroom. Language Arts, 80(6), 453-460. Retrieved from www.jstor.org/ stable/41484158

Villegas, A. M., SaizdeLaMora, K., Martin, A. D., \& Mills, T. (2018). Preparing future mainstream teachers to teach English language learners: A review of the empirical literature. The Educational Forum 82(2), 138-155. doi:10.108 $0 / 00131725.2018 .1420850$

Ester de Jong is a professor in ESOL/bilingual education and the director of the School of Teaching and Learning at the University of Florida. Her research focuses on bilingual education and preparing teachers to work with bilingual learners. Dr. de Jong was the 2017-2018 President of TESOL International Association. Her book, Foundations of Multilingualism in Education: From Policy to Practice published by Caslon Publishing, considers a principled approach to school, program, and classroom decision-making for multilingual learners.

edejong@coe.ufl.edu 
